\title{
Efeito da escarificação na condutividade hidráulica saturada de um Latossolo Vermelho sob plantio direto
}

\author{
The soil scarification effects in hydraulic conductivity of the Red Latosol (Oxisol) under No-tillage system
}

\author{
João Tavares-Filho $^{1^{*}}$ Inês Cristina de Batista Fonseca ${ }^{1}$ Adriana Aparecida Ribon ${ }^{2}$ \\ Graziela Moraes de Cesare Barbosa²
}

\begin{abstract}
O cultivo intensivo dos solos das regiões tropicais
cais somente torna se viável dentro do contexto de RESUMO e subtropicais somente torna se viável dentro do contexto de
uma agricultura sustentável através do uso de tecnologias apropriadas que assegurem uma eficiência produtiva, sem degradação do solo. O presente estudo teve por objetivo analisar in situ os efeitos da escarificação na condutividade hidráulica saturada de um Latossolo Vermelho distroférrico sob plantio direto por mais de vinte anos. A condutividade hidráulica saturada do solo escarificado aumentou de forma significativa em 1,45 $10^{-5} \mathrm{~m} \mathrm{~s}^{-1}$, porém um ano após essa escarificação, esse ganho foi reduzido para $0,4810^{-5} \mathrm{~m} \mathrm{~s}^{-1}$ e não mais diferiu do solo sob plantio direto contínuo.
\end{abstract}

Palavras-chave: manejo do solo, cultivo reduzido, densidade do solo, condutividade hidráulica saturada.

\section{ABSTRACT}

Intensive soil cultivation in tropical and subtropical regions is only viable within the context of the sustainable agriculture that ensures appropriated technologies that assures productive efficiency without soil degradation. The present in situ study was carried out to determine the effect of the soil scarification in the saturated hydraulic conductivity in a dystrophic Red Latosol (Oxisol) under no-tillage systems for 20 years. The results showed that the study of hydraulic conductivity in the soil under no-tillage system was significantly affected in $1.4510^{-5} \mathrm{~m} \mathrm{~s}^{-1}$ after soil scarification, but a year later this gain was greatly reduced for $0.4810^{-5} \mathrm{~m} \mathrm{~s}^{-1}$.

Key words: soil management, minimum tillage, bulk density, matric potential.
Nas regiões tropicais e subtropicais onde existe cultivo intensivo dos solos, o plantio direto tornou-se uma das tecnologias de cultivo de maior expressividade a partir da década de 80 , devido à conscientização da necessidade de preservação dos recursos naturais e por este ser um sistema de condução mais econômico a médio e longo prazo (DERPSCH et al., 1991).

Os Latossolos Vermelhos e os Nitossolos do norte do Paraná, que estão entre os solos mais produtivos do Brasil, vêm sendo cultivados em plantio direto; porém, em alguns casos, verifica-se atualmente, nesses solos, a presença de uma camada superficial (primeiros $0,15 \mathrm{~m}$ ) compactada, sendo este fato associado ao não revolvimento e ao tráfego de máquinas (TAVARES-FILHO \& TESSIER, 1998). Essa compactação superficial pode influenciar o desenvolvimento das plantas (SILVA \& KATTO, 1997; REICHERT et al., 1992) e diminuir a infiltração da água da chuva e, dessa forma, problemas de escoamento superficial poderão se fazer presentes (LOGSDON et al., 1990 ; ANKENY et al., 1990).

De acordo com CORRÊA (1985), a taxa final de infiltração é a característica mais sensível para detectar as modificações nas condições físicas do solo introduzidas pelo manejo. Como pode ser observado nos trabalhos de SILVA \& KATTO (1997) e ANKENY et al. (1990), estes autores, trabalhando com diferentes

${ }^{1}$ Universidade Estadual de Londrina (UEL), Centro de Ciências Agrárias (CCA), Agronomia, Caixa Postal 6001, 86051-990, Londrina, PR, Brasil. E-mail: tavares@uel.br. *Autor para correspondência.

${ }^{2}$ Programa de Pós-graduação em Agronomia da Universidade Estadual de Londrina (UEL), Caixa Postal 6001, 86051-990, Londrina, PR, Brasil 
sistemas de cultivo, constataram que esses sistemas de cultuivo alteram a porosidade e as propriedades hidráulicas dos solos cultivados. Variações na velocidade de infiltração estão relacionadas com atributos tais como densidade do solo, macro e microporosidade e condutividade hidráulica com o qual, segundo FREIRE (1979), é um parâmetro importante no manejo da água no solo. Trata-se de um processo físico de extrema complexidade, dado que o solo é um meio heterogêneo, com ampla variabilidade espacial, apresentando características que sofrem alterações diferenciadas no tempo e no espaço. Como essa propriedade é específica para cada solo, e devido aos fenômenos da água no solo serem dinâmicos e influenciáveis pelas camadas subjacentes, torna-se necessário identificá-la de forma global, na superfície do solo, para, a partir dessa caracterização, para cada tipo de manejo, compreender o todo.

Dessa forma, o presente estudo teve por objetivo analisar in situ os efeitos da escarificação na condutividade hidráulica saturada de um Latossolo Vermelho distroférrico sob plantio direto por mais de vinte anos. Para tal, foi conduzido um ensaio na Fazenda São Manoel, localizada na região Norte do Paraná, com latitude $22^{\circ} 57^{\prime} \mathrm{S}$, longitude $51^{\circ} 11^{\prime} \mathrm{W}$ e altitude média de 320 a 350m. O clima, segundo a classificação de Köppen (IAPAR, 1994), é o Cfa mesotérmico úmico, e o solo da área é classificado como Latossolo Vermelho distroférrico (EMBRAPA, 1999), textura muito argilosa. A análise granulométrica na camada de $0-0,15 \mathrm{~m}$ apresentou $710 \mathrm{~g} \mathrm{~kg}^{-1}$ de argila, $160 \mathrm{~g}$ $\mathrm{kg}^{-1}$ de silte e $130 \mathrm{~g} \mathrm{~kg}^{-1}$ de areia.

A propriedade agrícola em questão utiliza o sistema de plantio direto desde 1980 , tendo sido realizada, antes da implantação deste sistema, uma adequação da área, com eliminação de camadas compactadas, correção da acidez e da fertilidade do solo e implantação de terraços de base larga. Após 20 anos consecutivos no sistema de plantio direto, surgiram dúvidas quanto ao seu efeito na condutividade hidráulica do solo.

Assim, selecionou-se uma área de produção na propriedade e delimitou-se uma parcela com $10 \mathrm{x}$ $10 \mathrm{~m}$, declive de $1,2 \%$, onde foram feitas todas as determinações da condutividade hidráulica saturada do solo, na seqüência apresentada a seguir: 1a determinação: condutividade hidráulica em solo sob plantio direto por 20 anos (PD20 = tratamento 1); $2^{\text {a }}$ determinação: condutividade hidráulica em solo escarificado após 20 anos de plantio direto (Esc = tratamento 2); 3a determinação: condutividade hidráulica um ano após a escarificação (Esc1 = tratamento 3) e 4⿳亠口冋 determinação: condutividade hidráulica dois anos após a escarificação (Esc2=tratamento 4). A escarificação do solo foi realizada com um implemento de cinco hastes, espaçadas 0,30 m entre si, na profundidade de 0,25m, e com umidade igual a $0,17 \pm 0,02 \mathrm{~kg} \mathrm{~kg}^{-1}$, com a qual buscou-se atingir toda área de forma contínua

A determinação da condutividade hidráulica saturada foi feita in situ na superfície do solo de cada tratamento, utilizando um infiltrômetro multi-disco (raio do disco igual a $0,054 \mathrm{~m}$ ) de sucção controlada, por meio de um sistema chamado TRIMS (Triple Ring Infiltrometers at Multiple Succions), constituído de uma membrana permeável à água que, em contato com a superfície do solo, permite um escoamento controlado da água sob diferentes potenciais matriciais aplicados por meio de um dispositivo de Mariotte (PERROUX \& WHITE, 1988; ANKENY et al., 1991). No presente trabalho, determinou-se a condutividade hidráulica saturada (potencial matricial de água no solo igual a 0 $\mathrm{MPa}$ ). Para cada tratamento, foram escolhidos cinco pontos ao acaso, de forma inteiramente casualizada (sem distinção entre linha ou entrelinha). Considerando as irregularidades do solo, para garantir o contato da membrana permeável do infiltrômetro com o solo, a superfície era limpa, nivelada e recebia uma cobertura de areia fina.

Com intuito de padronizar todas as determinações, sabendo-se que a umidade inicial do solo, nos primeiros testes (tratamento PD20 e Esc), era de $0,17 \pm 0,02 \mathrm{~kg} \mathrm{~kg}^{-1}$, buscou-se realizar os testes de condutividade para os tratamentos Esc1 e Esc2, realizados um ano e dois anos após a primeira bateria de testes, também em uma condição de umidade similar. Após cada teste de condutividade hidráulica, foram coletadas amostras de solo em anéis volumétricos, na profundidade de $0-0,15 \mathrm{~m}$, próximas à zona onde foi feito o teste com o infiltrômetro, para a determinação da densidade do solo pelo método do anel volumétrico (EMBRAPA, 1997).

Por se tratar de um delineamento inteiramente casualisado com cinco repetições, para comparação dos resultados obtidos, foram determinados a média das cinco repetições, o intervalo de confiança de 95\% (nível de probabilidade de 5\%), além da análise de variância. Os resultados são apresentados em gráficos "Box Plots”.

Na figura 1 (A), são apresentados, os valores médios, máximos e mínimos e os desvios padrão da condutividade hidráulica saturada, em função dos diferentes tratamentos. Observa-se que a escarificação aumentou (PD - Esc = 3,60 10-5 $\mathrm{m} \mathrm{s}^{-1}$ ) a condutividade hidráulica saturada em comparação ao plantio direto contínuo. Por outro lado, o solo após 1 e 2 anos da 


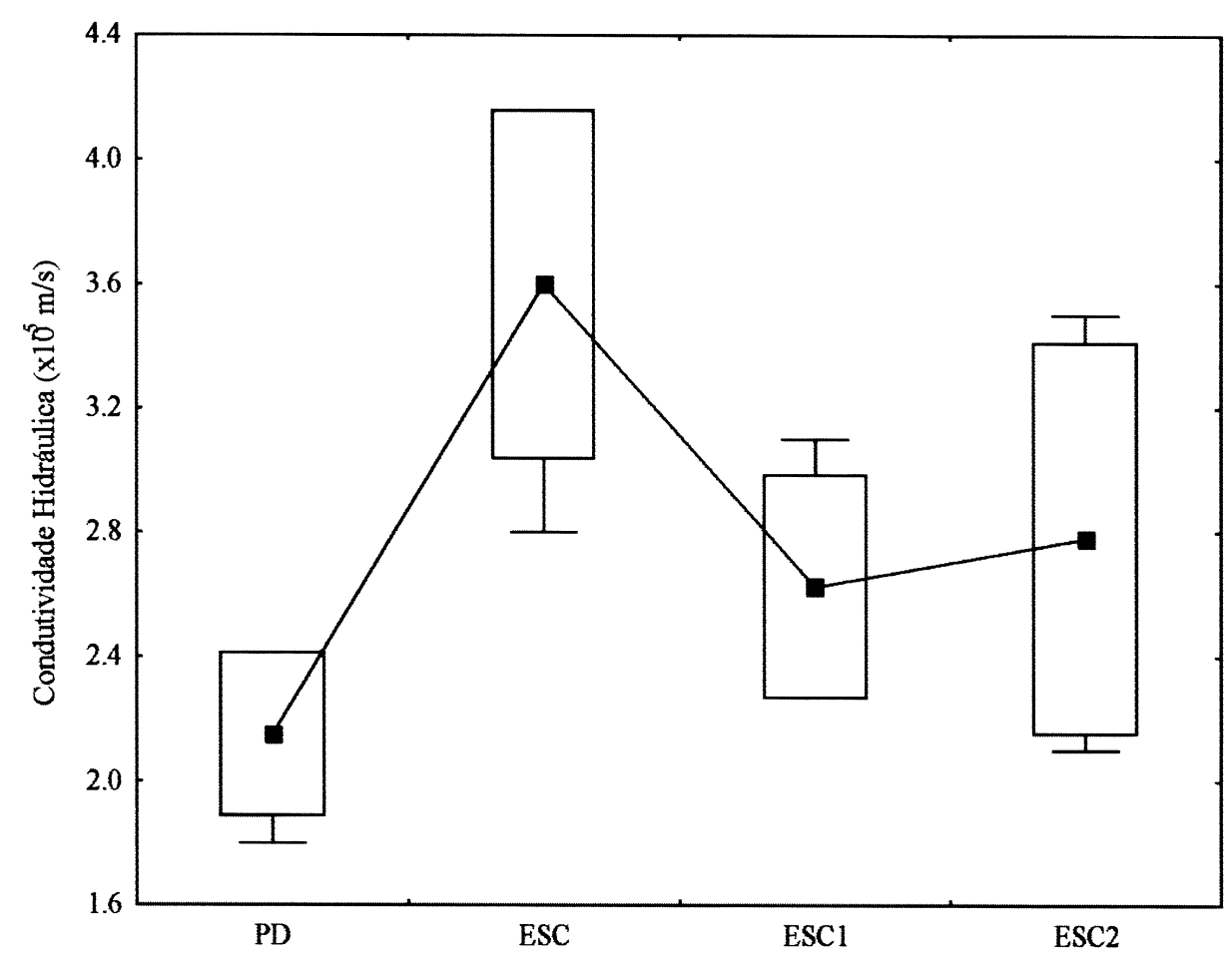

工 Máx Min

$\square$ Média+DP Média-DP

(A)

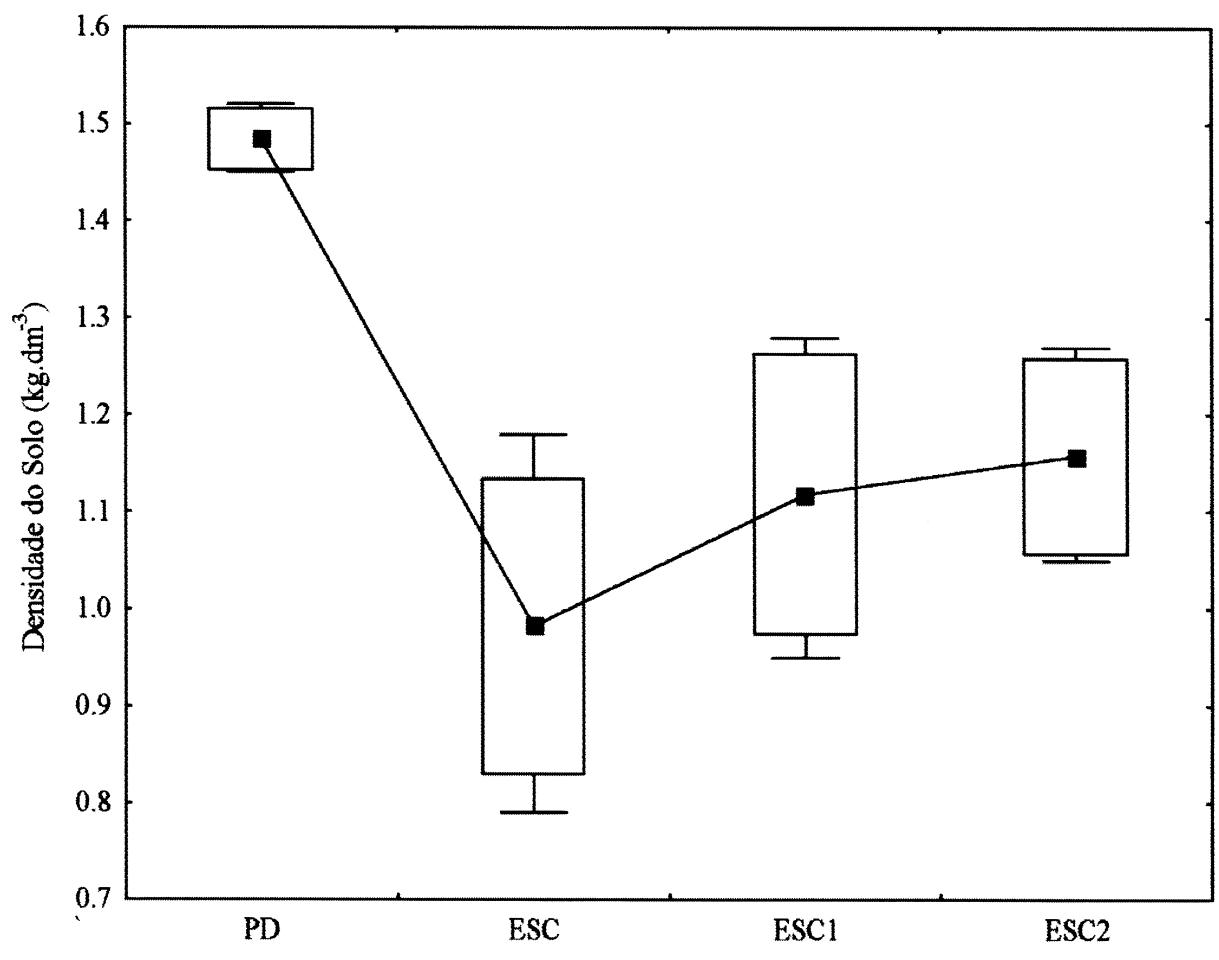

Média

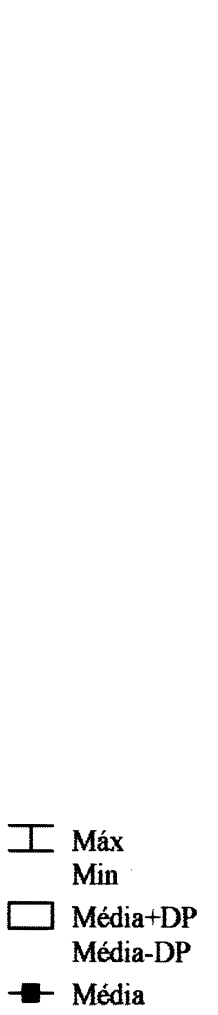

(B)

Figura 1 - Condutividade hidráulica saturada (A) e densidade do solo da camada superficial $(0-0,15 \mathrm{~m})$ (B) de um Latossolo Vermelho distroférrico. (PD20-Plantio direto por 20 anos, Esc- Escarificação após 20 anos de PD, Esc1-1 ano após a escarificação e Esc2-2 ano após a escarificação).

Ciência Rural, v.36, n.3, mai-jun, 2006. 
escarificação, apresentou uma redução da condutividade hidráulica saturada para valores intermediários ao plantio direto contínuo e plantio direto avaliados logo após a escarificação.

Essas diferenças constatadas (Figura 1 (A)), indicam que a condutividade hidráulica do solo escarificado foi 1,67 vezes maior que a do solo sob plantio direto, indicando que, após a escarificação, ocorreu uma elevação de $1,4510^{-5} \mathrm{~m} \mathrm{~s}^{-1}$ na condutividade hidráulica em relação ao solo sob plantio direto há 20 anos. Porém, esse ganho foi reduzido para $0,4810^{-5} \mathrm{~m} \mathrm{~s}^{-1}$ apenas um ano após a realização dessa escarificação, indicando que ocorre uma rápida reconsolidação do solo. SILVA \& KATTO (1997), trabalhando em Latossolo Vermelho Amarelo, constataram diferenças importantes na condutividade hidráulica saturada do solo sob plantio direto e sob manejo convencional, mostrando que pequenas diferenças na macroporosidade foram acompanhadas por elevadas diferenças de valores de condutividade hidráulica, sendo de $0,212 \mathrm{~cm} \mathrm{~min}^{-1}\left(3,5310^{-5} \mathrm{~m} \mathrm{~s}^{-1}\right)$ na área de plantio direto e de $1,359 \mathrm{~cm} \mathrm{~min}^{-1}\left(22,6510^{-5} \mathrm{~m} \mathrm{~s}^{-1}\right)$ na área de manejo convencional. RALISCH et al. (2001), trabalharam com resistência do solo à penetração e demostraram que os efeitos da escarificação no solo praticamente desaparecem no período de um ano, em solos sob plantio direto.

A fim de verificar o efeito da escarificação na redução da compactação superficial, determinouse a densidade do solo da camada superficial $(0-0,15 \mathrm{~m})$ (Figura 1 (B)). Os resultados mostram que a densidade do solo escarificado (Esc.) $\left(0,99 \mathrm{~kg} \mathrm{dm}^{-3}\right)$ foi significativamente menor do que a do tratamento PD20, porém não diferiu dos tratamentos Esc1 e Esc2. O maior valor de densidade do solo foi detectado no tratamento plantio direto $\left(1,48 \mathrm{~kg} \mathrm{dm}^{-3}\right)$, valor esse superior aos verificados nos tratamentos com escarificação (Esc1 = $\left.1,11 \mathrm{~kg} \mathrm{dm}^{-3} ; \operatorname{Esc} 2=1,16 \mathrm{~kg} \mathrm{dm}^{-3}\right)$.

A escarificação aumenta de forma significativa a infiltração da água no solo sob plantio direto, porém esse aumento não perdura por mais de um ano. Dessa forma, considerando que a escarificação é uma operação de custo relativamente alto em função da potência requerida, deve-se fazer um estudo minucioso de custo/benefício antes de se pensar nesta operação para resolver supostos problemas de compactação em áreas de plantio direto. Sistemas que incluem a rotação de culturas e a adoção de culturas de cobertura devem ser a primeira opção em áreas de plantio direto.

\section{REFERÊNCIAS}

ANKENY, M.D et al. Caracterization of tillage and traffic effects on unconfined infiltration measurement. Soil Science Society of American Journal, v.54, p.837-840, 1990.

ANKENY, M.D et al. Simple field method for determining unsaturated hydraulic conductivity. Soil Science Society of American Journal, v.55, p.467-470, 1991

CORRÊA, J.C. Efeito de métodos de cultivo em algumas propriedades físicas de um Latossolo Amarelo muito argiloso do Estado de Amazonas. Pesquisa Agropecuária Brasileira, v.20, p.1317-1322, 1985.

DERPSCH, R et al. Controle da erosão no Paraná, Brasil: sistemas de cobertura do solo, plantio direto e preparo conservacionista do solo. Eschborn: Deutsche Gesellschaff für Technische Zusammenarbeit (GTZ), 1991. 272p.

EMPRESA BRASILEIRA DE PESQUISA AGROPECUÁRIA EMBRAPA. Centro Nacional de Pesquisa de Solos (Rio de Janeiro, RJ). Sistema Brasileiro de Classificação de Solos. Brasília: Embrapa Produção de Informação, Rio de Janeiro, Embrapa Solos, 1999. 412p.

EMPRESA BRASILEIRA DE PESQUISA AGROPECUÁRIA EMBRAPA. Manual de métodos de análise de solo. 2.ed. Rio de Janeiro, 1997. 212p.

FREIRE, J.C. Condutividade hidráulica e capacidade de campo em um Latossolo Roxo distrófico não saturado. Revista Brasiseila de Ciência do Solo, v.3, p.73-77, 1979.

INSTITUTO AGRONOMICO DO PARANÁ - IAPAR. Área de Ecofisiológia, Rede de Estações Agrometeorológicas do Instituto Agronômico do Paraná. Cartas Climáticas Básicas do Estado do Paraná. Londrina, 1994. 240p.

LOGSDON, S.D. et al. Macroporosity and its relation to saturated hydraulic conductivity under different tillage practices. Soil Science Society of American Journal, v.54, p.10961101, 1990.

PERROUX, K.M.; WHITE, I. Designs for disc permeameters. Soil Science Society of American Journal, v.52, p.12051215, 1988.

RALISCH, R. et al. Avaliação em um solo argiloso sob plantio direto de uma escarificação na evolução da resistência do solo à penetração. In: CONGRESSO BRASILEIRO DE ENGENHARIA AGRÍCOLA, 23., 2001, Foz-de-Iguaçu. Anais... Foz-de-Iguaçu: SBEA, 2001. CD Rom.

REICHERT, J.M. et al. Selamento superficial e infiltração de água em solos do Rio Grande do Sul. Revista Brasileira de Ciência do Solo, v.16, p.289-298, 1992.

SILVA, C.L.; KATO, E. Efeitos do selamento superficial na condutividade hidráulica saturada da superfície de um solo sob cerrado. Pesquisa Agropecuária Brasileira, v.31, p.593597, 1997.

TAVARES FILHO, J.; TESSIER, D. Influence des pratiques culturales sur le comportement et les propriétés de sols du Paraná (Brésil). Étude et Gestion dês Sols, Paris, v.5, p.61-71, 1998. 